\title{
Verrucous carcinoma (carcinoma cuniculatum) of the head and neck: what do we know now that we did not know a decade ago?
}

\author{
Kenneth O. Devaney • Alfio Ferlito • \\ Alessandra Rinaldo • Adel K. El-Naggar · Leon Barnes
}

Received: 4 January 2011 / Accepted: 11 January 2011 / Published online: 1 February 2011

(C) Springer-Verlag 2011

\section{Introduction}

Verrucous carcinoma was first reported by Friedell and Rosenthal [1], who described eight lesions of a verrucoid nature in the buccal mucosa and alveolar ridge of tobacco chewers. In 1948, one of the deans of US surgical pathology, Lauren V. Ackerman [2] reported on a vexing lesion arising in the head and neck region. This lesion was a squamoproliferative lesion with a capacity for locally destructive behavior, but a most deceptively bland light microscopic appearance. Ackerman [2] clearly defined the morphological and biological features of this neoplasm, coining the term "verrucous carcinoma". At roughly the

This paper was written by members of the International Head and Neck Scientific Group (http://www.IHNSG.com).

K. O. Devaney

Department of Pathology,

Allegiance Health, Jackson, MI, USA

A. Ferlito $(\varangle) \cdot$ A. Rinaldo

ENT Clinic, University of Udine,

Piazzale S. Maria Della Misericordia,

33100 Udine, Italy

e-mail: a.ferlito@uniud.it

\section{A. K. El-Naggar}

Department of Pathology and Head and Neck Surgery,

The University of Texas M.D. Anderson Cancer Center,

Houston, TX, USA

\section{Barnes}

Department of Pathology,

University of Pittsburgh School of Medicine,

Pittsburgh, PA, USA same time, a prominent British surgeon, Aird reported a similar lesion arising from the skin of the foot [3]. Both of these reports-Ackerman's verrucous carcinoma and Aird's carcinoma cuniculatum (so named because of the resemblance of the deeply infiltrating tongues of tumor to rabbit burrows)-described the same lesion arising in different locales, a lesion marked by an exophytic warty appearance and a tendency to push deeply into the underlying tissues.

Verrucous carcinoma is now known to arise in a variety of epithelial sites, most often the oral mucosa, the larynx, the skin of the genitalia, and the skin of the plantar aspect of the foot [4-7]. Cervical and distant metastases have not been reported in cases of classic verrucous carcinoma [8, 9]. Histological examination of any enlarged lymph nodes has revealed only reactive changes and not metastases [9]. Virtually all cases of alleged metastatic verrucous carcinomas are conventional exophytic well-differentiated carcinomas mislabeled as verrucous or they are unrecognized hybrid verrucous carcinomas. This tumor poses chiefly a problem in local control only, in light of its locally destructive character.

\section{Diagnosis of verrucous carcinoma}

As a clinical matter, verrucous carcinomas manifest as exophytic masses, typically with - as the name suggests-a papillomatous, or verrucous, surface; less often, the surface has less of a "warty" appearance, and on occasion may even appear relatively smooth. These are slowly growing tumors, seen chiefly in men in the sixth and seventh decades of life; oftentimes, they have been present for over a decade before a diagnosis of verrucous carcinoma is made. When verrucous carcinomas arise in close proximity 
to bone- in the vicinity of the mandible, for example, they can invade the underlying periosteum and the underlying bone [10].

It is in the realm of pathologic diagnosis that verrucous carcinomas have won a degree of notoriety, as they are particularly difficult to diagnose by histologic examination of small superficial biopsy specimens. Working from the outermost aspect of the tumor down toward its deepest extent, the light microscopic appearances of a verrucous carcinoma as a rule follow this stereotyped pattern: first, the superficial aspect of the lesion is composed of a thick layer of orthokeratotic or parakeratotic scale. Beneath that, there is an orderly pattern of maturing squamous epithelial cells, without either the cytologic atypia or the mitotic activity characteristic of a conventional squamous carcinoma. Finally, the deepest extent of this tumor is made up of distinctly broad rete ridges which appear to push their way deep into the subcutaneous or submucosal tissues (likened by some observers to "elephant feet" pushing their way down into the underlying tissues).

As they present as exophytic, "warty" lesions, it is not at all uncommon for biopsy specimens to sample only the most superficial portions of the tumors; it is for this reason, coupled with the bland cytologic appearance of the component cells, that verrucous carcinomas are often fiendishly difficult to diagnose by light microscopy at the time of initial biopsy examination. This is an example of the sort of tumor whose neoplastic nature (by virtue its characteristics on physical examination) is often better appreciated by the attending surgeon than by the pathologist examining a small portion of tissue in isolation.

Differential diagnostic considerations include both benign and malignant entities [11]. Not all white, verrucous lesions of the head and neck will prove to be verrucous carcinomas; true viral verruca, verrucous hyperplasia, and squamous papillomas all enter into the differential diagnosis. From a purely light microscopic perspective, pseudoepitheliomatous hyperplasia (as one might to find overlying a granular cell tumor, for example) might suggest the possibility of a verrucous carcinoma on initial pathologic study. All of these benign differential diagnostic considerations have one thing in common: they all lack the deep downward invasion of the adjacent soft tissues by broad columns of squamous epithelium seen in an adequate biopsy specimen from a verrucous carcinoma.

At the opposite end of the biological spectrum, conventional squamous carcinomas (as well as pre-malignant squamous dysplasia) may be surmounted by a hyperkeratotic or verrucous surface. These more aggressive lesions, however, are marked by both a greater degree of cytologic atypia among the component cells (although admittedly the differences in degree of atypia may at times be subtle) and by a greater degree of mitotic activity.
Hybrid verrucous carcinoma

There are two types of verrucous carcinomas: classic and hybrid. The more common classic variant, as previously described, is a histologically uniform or pure tumor that may be locally aggressive, but does not metastasize. The hybrid verrucous carcinoma, in contrast, is a mixed tumor composed of both verrucous and conventional squamous cell carcinoma that is capable of metastasizing.

The hybrid form is not uncommon as some studies indicate that about $20 \%$ of all oral and $10 \%$ of all laryngeal verrucous carcinomas are of the hybrid type [12-14]. Johnson et al. [15] found minute foci of invasive squamous carcinoma in 3 of the 13 patients (23\%) with verrucous carcinoma of the penis; yet, many clinicians as well as pathologists are not aware of it.

All verrucous carcinomas should, therefore, be thoroughly evaluated to exclude a potential hybrid variant. If recognized, the pathologist should quantitate each component of the tumor (e.g. 70\% verrucous carcinoma and $30 \%$ conventional squamous cell carcinoma), indicate the degree of differentiation of the squamous component, and comment on the depth of invasion, presence or absence of angiolymphatic or perineural invasion and the adequacy of the resection margins. These features will help the surgeon to decide if additional therapy may be warranted, such as a neck dissection.

\section{Treatment of verrucous carcinoma}

The classical treatment of verrucous carcinomas can be summed up in two words: surgical excision; the great majority of verrucous carcinomas have been cured by complete surgical excision $[5,11,16,17]$. Patients receiving initial treatment with surgery enjoyed better survival than did those treated with irradiation, especially for cases originating in the oral cavity, as suggested by the National Cancer Database records of 2,350 cases of verrucous carcinoma of the head and neck [18]. While newer, competing treatment strategies are being explored (and will be discussed in the paragraphs below), the traditional approach-a most successful one, to be sure-has depended on the surgeon's skills. Patients with a conventional squamous cell carcinoma coexistent with a verrucous lesion should be treated as if they had invasive squamous cell carcinoma [14].

\section{New ideas about the genesis and treatment of verrucous carcinoma}

And so; what has changed in our understanding of verrucous carcinoma in the last few years? This form of cancer 
is often seen in those who chew tobacco or use snuff orally, so much so that it is sometimes referred to as "Snuff dipper's cancer." It was once thought that there was a strong link between the development of oral verrucous carcinomas and the use of chewing tobacco [17]; that link is now not thought to be such a strong one, although tobacco smoking, as is the case with conventional squamous carcinomas, is associated with the development of verrucous carcinomas of the oral cavity [4]. Alcohol use seems to share the same association with the development of verrucous carcinoma as it does with conventional squamous carcinoma $[11,16,17]$.

It now seems as though the genital region verrucous carcinomas are often associated with human papillomavirus (HPV) infection (in particular, with HPV types 6, 11, 16 and 18); the association between head and neck verrucous carcinomas and HPV, however, is less tight [19, 20].

As noted above, surgical excision is the mainstay of treatment of verrucous carcinoma. Lesions not amenable to surgical excision have been treated by radiation therapy in some instances; while this therapeutic approach has proven successful (albeit not as successful as surgical excision) [21], there has been some resistance to the use of radiation owing to (rare) reports of transition from the lowgrade verrucous carcinoma to a high-grade metastasizing tumor following radiation therapy. More recent reports, however, have not found an appreciable incidence of transition of the tumors to a more aggressive type; it now appears as though radiation therapy, for patients in whom surgical cure is not an option, will provide a satisfactory alternative [22].

Carbon dioxide laser therapy is being explored in the treatment of head and neck verrucous carcinomas [23, 24]. Although some patients treated by laser therapy have experienced local recurrences, this modality, like radiation therapy, seems as though it will prove to be an attractive alternative to surgery, at least in selected patients.

Chemotherapy might not, at first, seems to be a likely treatment for an indolent, slowly growing lesion with not much mitotic activity. Nevertheless, intraarterial infusion of methotrexate has recently been reported to yield some surprising responses in verrucous carcinoma patients who were not otherwise candidates for surgical cures $[25,26]$. Preliminary results have suggested that continuous infusion chemotherapy might be a successful alternative to surgery in the local control of verrucous carcinomas-indeed, one report claimed a $100 \%$ local control rate at a mean followup time of 42 months [25].

Molecular studies of verrucous carcinomas have yielded mixed results. There appear to be quantitative differences in protein expression (in particular, basement membrane elements including laminin, laminin-5, collagen IV, and fibronectin) between verrucous carcinomas, on the one hand, and squamous carcinoma in situ/invasive squamous carcinoma, on the other hand [27]. These differences, however, have proven to be subtle and do not yet seem to have achieved the precision called for in differential diagnosis.

Perhaps, a more pressing differential diagnostic is posed by the need to distinguish verrucous carcinoma from a form of verrucous hyperplasia [28]. Some authors have been able to detect differences in P53 and Ki67 expression between verrucous carcinoma and both benign verrucous hyperplasias and conventional squamous carcinomas; less difference was found in the expression of p16, p21, and retinoblastoma gene product (RBGP) [29, 30]. Other authors, however, have not been able to reproduce these results [31,32]. Thus, the search for probes to refine the pathologic diagnostic criteria for verrucous carcinoma continues.

This, then, is where we stand with verrucous carcinoma (carcinoma cuniculatum)-newer treatment modalities to supplement the traditional mainstay of surgical excision are in development; we are beginning to unlock some of the molecular attributes of these tumors; and new probes for differential diagnosis are being examined, to supplement routine light microscopy. There is the reason for optimismthese advances may yet bring a time when verrucous carcinomas are no longer thought of as relentlessly destructive lesions, as they become increasingly easy to both diagnose and treat, as our knowledge about them grows.

\section{References}

1. Friedell HL, Rosenthal LM (1941) The etiologic role of chewing tobacco in cancer of the mouth. Report of eight cases treated with radiation. JAMA 116:2130-2135

2. Ackerman LV (1948) Verrucous carcinoma of the oral cavity. Surgery 23:670-678

3. Aird I, Johnson HD, Lennox B, Stansfeld AG (1954) Epithelioma cuniculatum: a variety of squamous carcinoma peculiar to the foot. Br J Surg 42:245-250

4. Kraus FT, Perez-Mesa C (1966) Verrucous carcinoma. Clinical and pathologic study of 105 cases involving oral cavity, larynx and genitalia. Cancer 19:26-38

5. Ferlito A, Recher G (1980) Ackerman's tumor (verrucous carcinoma) of the larynx. A clinicopathologic study of 77 cases. Cancer 46:1617-1630

6. Puxeddu R, Cocco D, Parodo G, Mallarini G, Medda M, Brennan PA (2008) Carcinoma cuniculatum of the larynx: a rare clinicopathological entity. J Laryngol Otol 122:1118-1123

7. Pons Y, Kerray S, Cox A, Guerre A, Bertolus C, Gruffaz F, Capron F, Goudot P, Ruhin-Poncet B (2010) Mandibular cuninulatum carcinoma: a propose of 3 cases and literature review. Head Neck [Epub ahead of print]

8. Oliveira DT, de Moraes RV, Fiamengui Filho JF, Fanton Neto J, Landman G, Kowalski LP (2006) Oral verrucous carcinoma: a retrospective study in São Paulo Region, Brazil. Clin Oral Investig 10:205-209

9. Walvekar RR, Chaukar DA, Deshpande MS, Pai PS, Chaturvedi P, Kakade A, Kane SV, D'Cruz AK (2009) Verrucous carcinoma of 
the oral cavity: a clinical and pathological study of 101 cases. Oral Oncol 45:47-51

10. Rekha KP, Angadi PV (2010) Verrucous carcinoma of the oral cavity: a clinico-pathologic appraisal of 133 cases in Indians. Oral Maxillofac Surg 14:211-218

11. Thomas GJ, Barrett AW (2009) Papillary and verrucous lesions of the oral mucosa. Diagn Histopathol 15:279-285

12. Kolokythas A, Rogers TM, Miloro M (2010) Hybrid verrucous squamous carcinoma of the oral cavity: treatment considerations based on a critical review of the literature. Oral Maxillofac Surg 68:2320-2324

13. Medina JE, Dichtel W, Luna MA (1984) Verrucous-squamous carcinomas of the oral cavity. A clinicopathologic study of 104 cases. Arch Otolaryngol 110:437-440

14. Orvidas LJ, Olsen KD, Lewis JE, Suman VJ (1998) Verrucous carcinoma of the larynx: a review of 53 patients. Head Neck 20:197-203

15. Johnson DE, Lo RK, Srigley J, Ayala AG (1985) Verrucous carcinoma of the penis. J Urol 133:216-218

16. McDonald JS, Crissman JD, Gluckman JL (1982) Verrucous carcinoma of the oral cavity. Head Neck Surg 5:22-28

17. Shafer WG (1972) Verrucous carcinoma. Int Dent J 22:451-459

18. Koch BB, Trask DK, Hoffman HT, Karnell LH, Robinson RA, Zhen W, Menck HR, Commission on Cancer, American College of Surgeons; American Cancer Society (2001) National survey of head and neck verrucous carcinoma: patterns of presentation, care, and outcome. Cancer 92:110-120

19. Syrjänen S (2005) Human papillomavirus (HPV) in head and neck cancer. J Clin Virol 32:S59-S66

20. Torrente MC, Rodrigo JP, Haigentz M Jr, Dikkers FG, Rinaldo A, Takes RP, Olofsson J, Ferlito A (2010) Human papillomavirus infections in laryngeal cancer. Head Neck [Epub ahead of print]

21. Ferlito A, Rinaldo A, Mannarà GM (1998) Is primary radiotherapy an appropriate option for the treatment of verrucous carcinoma of the head and neck? J Laryngol Otol 112:132-139

22. Huang SH, Lockwood G, Irish J, Ringash J, Cummings B, Waldron J, Kim J, Dawson LA, Bayley A, Hope A, O'Sullivan B (2009) Truths and myths about radiotherapy for verrucous carcinoma of larynx. Int J Radiat Oncol Biol Phys 73:1110-1115
23. Galimberti D, Galimberti G, Pontón Montaño A, Jácome LR, Galimberti R (2010) Oral verrucous carcinoma treated with carbon dioxide laser. J Eur Acad Dermatol Venereol 24:976-977

24. Hod R, Feinmesser R, Shvero J (2010) Carbon dioxide laser cordectomy for verrucous carcinoma of vocal folds. J Laryngol Otol 124:55-58

25. Fu C-F, Chen C-M, Shen Y-S, Huang I-Y, Chen C-H, Chen C-Y, Shieh T-Y, Sheen M-C (2008) Effective eradication of oral verrucous carcinoma with continuous intraarterial infusion chemotherapy. Head Neck 30:611-617

26. Strojan P, Ferlito A, Wu C-F, Rinaldo A (2010) Intraarterial chemotherapy: a valid option in the treatment of verrucous carcinoma? Eur Arch Otorhinolaryngol 267:835-837

27. Arduino PG, Carrozzo M, Pagano M, Broccoletti R, Scully C, Gandolfo S (2010) Immunohistochemical expression of basement membrane proteins of verrucous carcinoma of the oral mucosa. Clin Oral Investig 14:297-302

28. Lewis JS Jr (2010) Not your usual cancer case: variants of laryngeal squamous cell carcinoma. Head Neck Pathol [Epub ahead of print]

29. Adegboyega PA, Boromound N, Freeman DH (2005) Diagnostic utility of cell cycle and apoptosis regulatory proteins in verrucous squamous carcinoma. Appl Immunohistochem Mol Morphol 13:171-177

30. Klieb HB, Raphael SJ (2007) Comparative study of the expression of p53, Ki67, E-cadherin and MMP-1 in verrucous hyperplasia and verrucous carcinoma of the oral cavity. Head Neck Pathol 1:118122

31. Lin HP, Wang YP, Chiang CP (2010) Expression of p53, MDM2, p21, heat shock protein 70, and HPV 16/18 E6 proteins in oral verrucous carcinoma and oral verrucous hyperplasia. Head Neck [Epub ahead of print]

32. de Spíndula-Filho JV, da Cruz AD, Oton-Leite AF, Batista AC, Leles CR, de Cássia Gonçalves Alencar R, Saddi VA, Mendonça EF (2010) Oral squamous cell carcinoma versus oral verrucous carcinoma: an approach to cellular proliferation and negative relation to human papillomavirus (HPV). Tumour Biol [Epub ahead of print] 